f. med. Genet. (1969). 6, 85.

\title{
Trisomy-16 in a Mosaic Carrier Father and his Aborted Foetus ${ }^{\star}$
}

\author{
DAVID T. ARAKAKI $\dagger$ and SORRELL H. WAXMAN† \\ From the Department of Genetics, School of Medicine, University of Hawaii
}

Of the 22 possible autosomal trisomies in man, only 3 (trisomies-13, -18, -21 ) are found regularly in live births. Similar results have been obtained by cytogenetic studies of spontaneous abortions. In live births, trisomy-18 is the commonest trisomy involving the $E$ group, with only 2 apparent cases of a trisomy-16 having been reported (Lewis et al., 1963; Melnyk, Thompson, and Hecht, 1967). In spontaneous abortion, trisomy-16 occurs at a relatively high frequency if trisomy of the $\mathbf{E}$ group is found (66\%, World Health Organization, 1966; 77\%, Inhorn, 1967).

We present here the results of a chromosomal analysis on a spontaneously aborted foetal specimen and both parents. The foetus and the father showed the trisomy-16 condition. The mother has had repeated abortions.

\section{Subjects and Methods}

The parents are Japanese and clinically appear normal. There have been no known exposures to teratogenic or mutagenic agents. There is no history of congenital anomalies or mental retardation on either side of the family pedigree. Three maternal sisters, however, have had miscarriages.

There have been 5 pregnancies resulting in one living, healthy child, and 4 abortions occurring at 3 to 4 months' gestation. The maternal age at the time of the index abortion was 37 years; paternal age was 39 years. The date of the last menstrual period was February 12, 1965, and the date of abortion was May 24, 1965 . The mother experienced vaginal spotting throughout this pregnancy, with cramping and bleeding one day before the abortion.

No foetus was present in the aborted material. The chorion was cultured as well as skin biopsies and peripheral blood samples of the parents.

Chromosomes were prepared according to previously described techniques (Arakaki and Sparkes, 1963; Arakaki, Waxman, and Smith, 1967).

\footnotetext{
Received July 19, 1968.

* Request reprints from Cytogenetics Laboratory, Kapiolani Maternity Hospital, Honolulu, Hawaii 96822.

† Supported in part by USPHS NIH grants HD-01133 and HD02159.
}

Results

The results of this study are summarized in the Table and Fig. 1 and 2.

TABLE

SUMMARY OF CHROMOSOMAL ANALYSES

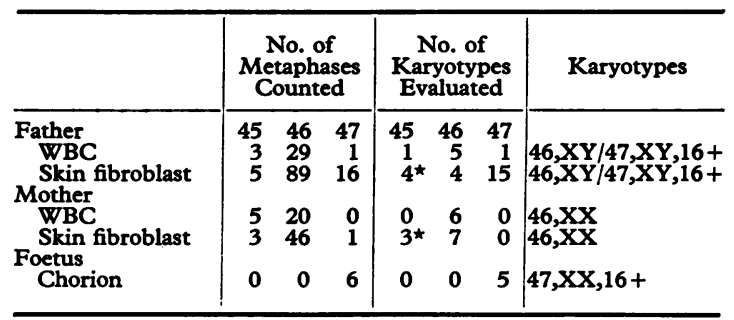

$\star$ No consistent pattern.

Abortus. We were able to obtain only 6 good cells in metaphase from this chorionic culture. Five of these cells were karyotyped and all were found to be trisomic for chromosome No. 16 $(47, \mathrm{XX}, 16+)$.

Parents. The mother was found to have the normal chromosome constituent in both her leucocytes and skin fibroblasts $(46, \mathrm{XX})$.

The father was found to be a mosaic in both his leucocyte and skin fibroblasts. Approximately 3\% of his leucocytes and $15 \%$ of his skin fibroblasts had a trisomy-16 chromosomal pattern. The remainder of his cells had a normal chromosomal pattern $(46, X Y / 47, X Y, 16+)$.

\section{Discussion}

It is of interest that this family was ascertained by two current projects in our laboratories. One is a cytogenetic study of parents in which the mother habitually aborts (three or more consecutive abortions). The other is a cytogenetic study of parents ascertained through our spontaneous foetal abortion project, because the product of their conception has been found to be chromosomally abnormal. There 

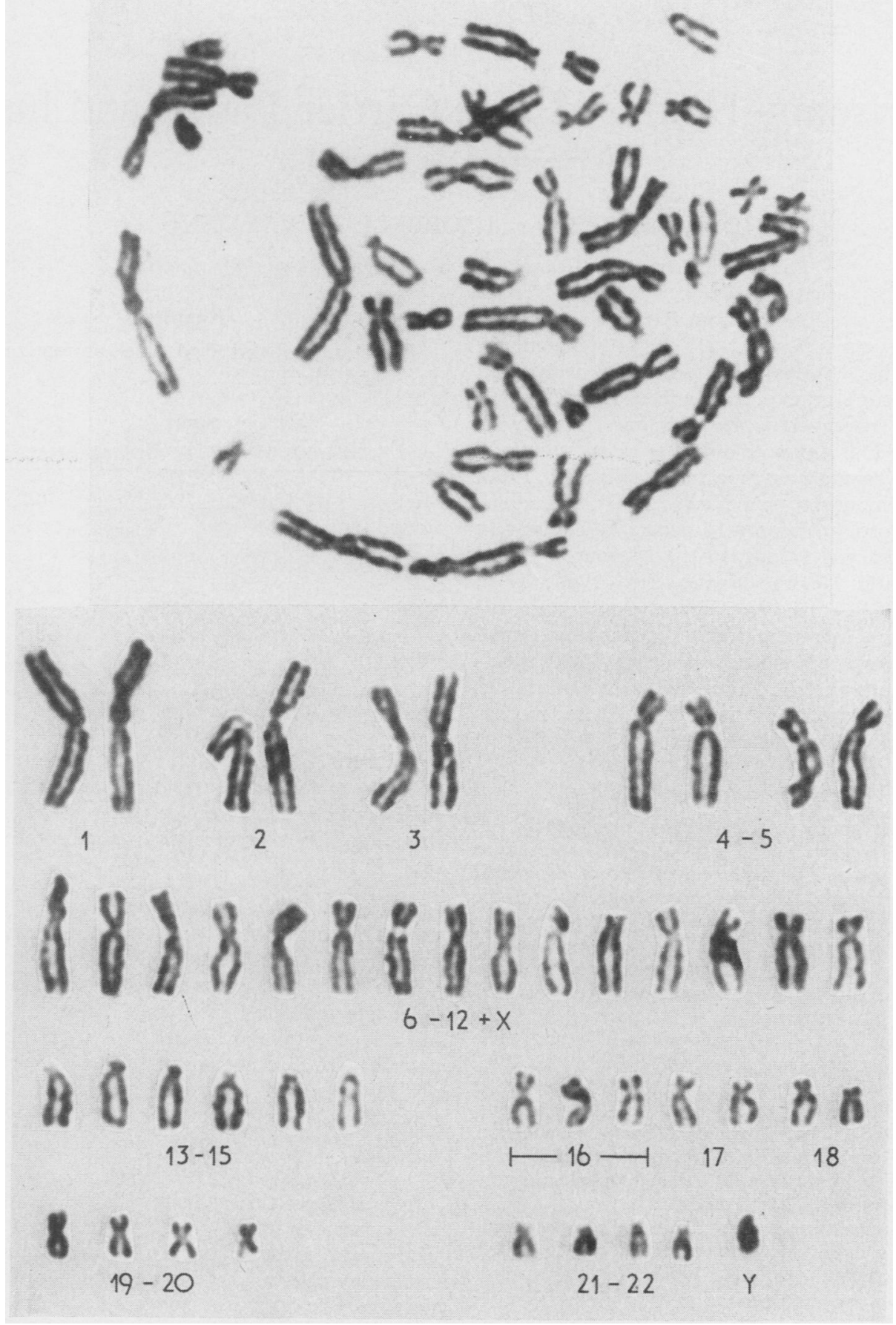

Fig. 1a, b. Metaphase plate and karyotype from father showing trisomy-16. 


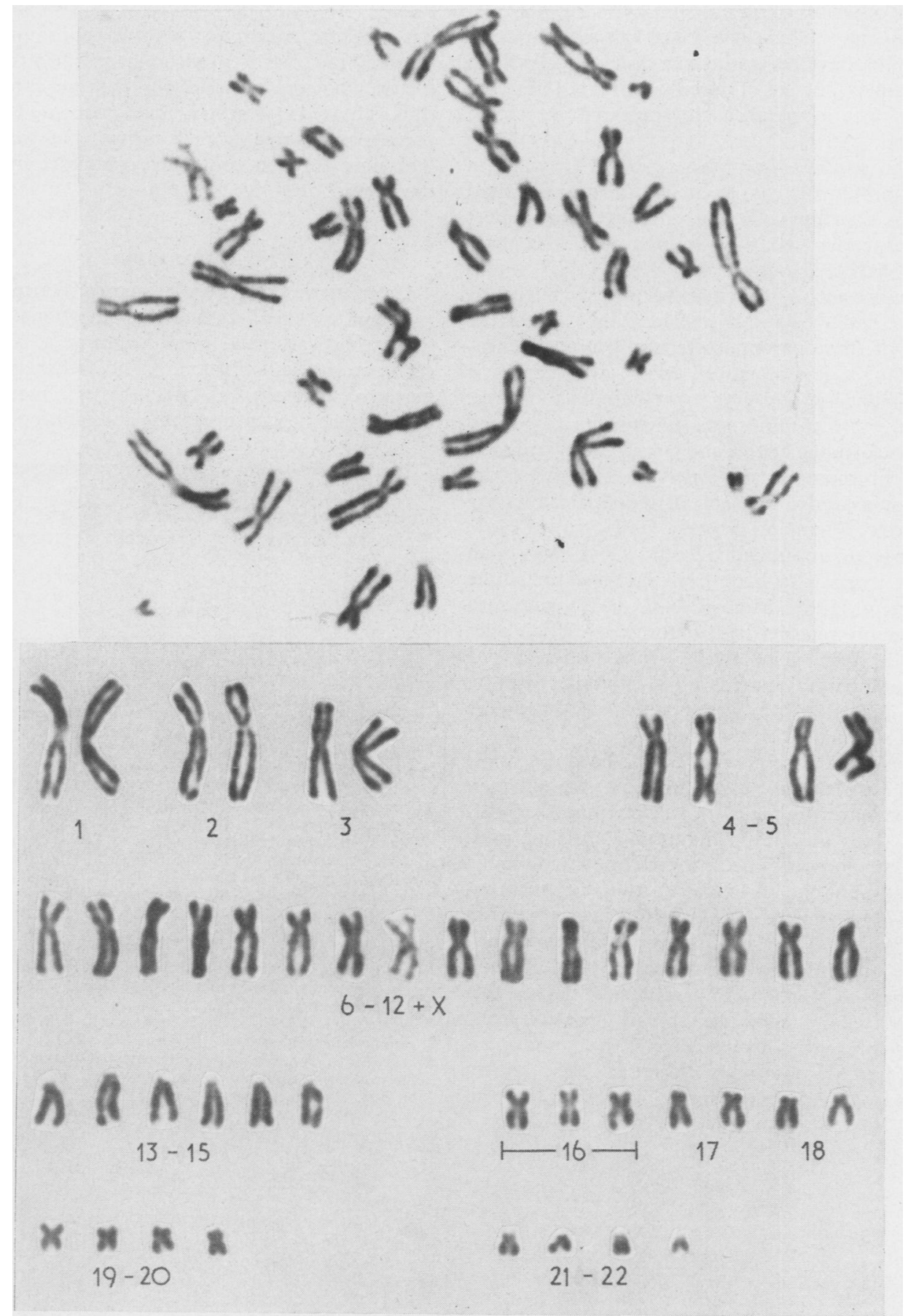

FIG. 2a, b. Metaphase plate and karyotype from foetus showing trisomy-16 and XX sex chromosome complement. 
are approximately 40 families in each of these groups. Only one other set of parents has had a similar dual ascertainment. They have been lost to follow-up. Ten families have been studied cytogenetically from each group. The set of parents presented here are the only ones in which a chromosomal aberration was found.

Though studies have been reported in which a mosaic individual has been found to have had numerous abortions, there is only one other report of a prospective study of women who habitually abort. McKay, Hodgkin, and Withe (1967) found in 42 couples with repeated abortions, two husbands who have had a balanced translocation. Since the foetuses of these parents were not examined chromosomally, it is impossible to tell whether their translocations had anything to do with the abortions.

Trisomy for chromosome 16 appears to be extremely rare in live births, and is well documented as a lethal chromosomal aberration in early foetal life. In our own study, $50 \%$ of all foetal trisomics are trisomy-16 (Waxman, Arakaki, and Smith, 1967; Waxman et al., unpublished data). Two cases of an apparent trisomy-16 have been reported in adults (Lewis et al., 1963; Melnyk et al., 1967), and both were severely retarded and deformed. Their ages were 59 and 26, respectively. The father in our study was apparently normal physically and mentally. Though dermatoglyphs were not studied, there were no gross stigmata of a trisomic state.

Mosaicism of chromosome 16 has been described (Rowley and Hodges, 1967) in a 69-year-old man with myelofibrosis, and in six members of his family. This mosaicism involved a cell line with normal chromosomes and a cell line involving a translocation of one chromosome 16 to a $\mathrm{C}$ chromosome. The father in our study also had mosaicism of chromosome 16. In his case, the abnormal cell line was trisomic for chromosome 16. Though only a small proportion of his cells seem to have this abnormality, it appears that some of these abnormal cells were present in his gonads and that some of his sperm were chromosomally defective. Of 5 known pregnancies, there have been 4 abortions, one of which was examined and found to be a trisomy-16 $\mathbb{D}$ foetus. It could be postulated that in these ferti- $\mathbb{D}$ lizations the sperm carried two chromosome $16 \mathrm{~s} \stackrel{-}{\Rightarrow}$ (normal meiosis of a trisomic cell) resulting in a $\stackrel{\oplus}{\stackrel{S}{\leftrightarrows}}$ foetus who was trisomic for chromosome 16 and $\bar{C}$ thus aborted. The normal offspring of these parents originated from a normal paternal sperm. This normal sperm could have originated from either $\stackrel{D}{\square}$ the normal or abnormal stem-cell.

\section{Summary}

Cytogenetic studies are presented in a couple who have had repeated spontaneous abortions. One of their abortions was found to have a trisomy-16 chromosome constitution. The father was chromosomally mosaic with one of his cell lines containing a trisomy- 16 chromosome constitution.

The authors wish to thank the nursing staff and the Pathology Department of Kapiolani Maternity Hospital for their co-operation in the foetal study, and Dr. Edward Matsuoka for referring the parents for cytological study.

\section{REFERENCES}

Arakaki, D. T., and Sparkes, R. S. (1963). Microtechnique for culturing leukocytes from whole blood. Cytogenetics, 2, 57.

-, Waxman, S. H., and Smith, J. B. (1967). Endometrial and fetal cytogenetics. Amer. F. Obstet. Gynec., 97, 868.

Inhorn, S. L. (1967). Chromosomal studies of spontaneous abortions. In Advances in Teratology, Vol. 2. Ed. by D. H. M. Woollam. Academic Press, New York.

Lewis, F. J. W., Hyman, J. M., McTaggart, M., and Poulding, R. H. (1963). Trisomy of autosome 16. Nature (Lond.), 199, 404.

McKay, R. V., Hodgkin, W. E., and Withe, E. H. (1967). Chromosome of couples with repeated spontaneous abortions (abstract). The American Pediatric Society, Atlantic City.

Melnyk, J., Thompson, H., and Hecht, F. (1967). Cytogenetic studies in an apparent trisomy-16 (47,XY,16+). Personal communication (abstract) 6th Conference on Mammalian Cytology and Somatic Cell Genetics. Mammalian Chromosomes Newsletter, Vol. 9.

Rowley, J. D., and Hodges, G. R. (1967). Familial mosaicism with non-homology of chromosome pair No. 16. Personal communication (abstract) 6th Conference on Mammalian Cytology and Somatic Cell Genetics. ibid., Vol. 9.

Waxman, S. H., Arakaki, D. T., and Smith, J. B. (1967). Cytogenetics of fetal abortions. Pediatrics, 39, 425.

World Health Organization (1966). Standardization of procedures for chromosome studies in abortion. Bull. Wld Hlth Org., 34, 765. 